\title{
Hypoxia induces the expression of TET enzymes in HepG2 cells
}

\author{
GUOFU LIN, WENYU SUN, ZHI YANG，JINSHUAI GUO，HAIYANG LIU and JIAN LIANG \\ Department of The First General Surgery, The Fourth Affiliated Hospital of China \\ Medical University, Shenyang, Liaoning 110032, P.R. China
}

Received March 20, 2016; Accepted August 1, 2017

DOI: 10.3892/ol.2017.7063

\begin{abstract}
Hypoxia promotes tumor malignancy in solid tumors. One key mechanism by which this occurs is via epigenetic alteration. The present study demonstrates that hypoxia upregulates the expression of the ten-eleven-translocation 5-methylcytosine dioxygenase (TET) enzymes, which catalyze the conversion of 5-methylcytosine to 5-hydroxymethylcytosine $(5-\mathrm{hmC})$, thereby leading to elevated cellular 5-hmC levels in hepatoblastoma HepG2 cells. Hypoxia inducible factor- $1 \alpha(\mathrm{HIF}-1 \alpha)$ is the main transcription factor activated by hypoxia. A chemical inducer of $\mathrm{HIF}-1 \alpha, \mathrm{CoCl}_{2}$, also increases the expression of TET enzymes. Knockdown of HIF-1 $\alpha$ attenuates the hypoxia-induced expression of TET enzymes. These results indicate that hypoxia controls DNA methylation through HIF-1 $\alpha$-mediated TET enzyme regulation in HepG2 cells.
\end{abstract}

\section{Introduction}

Primary liver cancer, predominantly hepatocellular carcinoma (HCC) and hepatoblastoma (HB), one of the most common solid tumors, is the most common cause of cancer-associated mortality worldwide (1-4). HCC is the most common liver tumor in adolescents and adults. HCC alone is the fifth most common newly diagnosed cancer and the third leading cause of cancer mortality worldwide $(1,2)$, while $\mathrm{HB}$ is the most common liver malignant tumor diagnosed by the age of 4 years, accounting for $80 \%$ of liver cancers in children under the age of 15 years $(5,6)$. Among patients with localized HB or HCC, surgical resection is a common treatment option. Liver transplantation is considered to be the only curative therapy; however, the majority of patients with advanced HB or HCC are not suitable for transplantation (3,4,6,7). Currently,

Correspondence to: Dr Jian Liang, Department of The First General Surgery, The Fourth Affiliated Hospital of China Medical University, 4 Chongshandonglu, Huanggu, Shenyang, Liaoning 110032, P.R. China

E-mail: jianliang328@163.com

Key words: hypoxia, ten-eleven-translocation 5-methylcytosine dioxygenase, hypoxia inducible factor-1 $\alpha, 5$-hydroxymethylcytosine, methylation chemotherapy utilized to treat patients with unresectable HCC results in a poor response and severe toxicity (7). Thus, more effective agents to combat primary liver cancer are in high demand.

Although the molecular pathogenesis of $\mathrm{HCC}$ and $\mathrm{HB}$ remains unclear, liver cirrhosis is acknowledged as a premalignant condition for developing HCC (8). Deregulation of a number of oncogenes, including c-MYC, cyclin D1 and $\beta$-catenin, has been observed in $\operatorname{HCC}(2,9)$. The expression of certain tumor-suppressor genes, including those expressing retinoblastoma protein, deleted in liver cancer $1, \mathrm{P}^{\mathrm{INK} 4 \mathrm{~A}}, \mathrm{P} 53$ and E-cadherin, is changed in $\operatorname{HCC}(2,10)$. HB is considered to arise from hepatic progenitors or hepatoblasts $(11,12)$. Mutations in catenin beta 1 and other components of the $\beta$-catenin degradation complex, including adenomatous polyposis coli and axis inhibition protein 2 , have been reported (13-17). Recent studies indicated that genome-wide DNA hypomethylation and promoter $\mathrm{CpG}$ island hypermethylation contribute to the initiation and progression of $\mathrm{HB}$ and $\mathrm{HCC}$, and are correlated with poor survival (2,17-21).

Rapid cellular proliferation and abnormal vasculature in solid tumors such as HCC result in a highly hypoxic environment in which the expression of hypoxia inducible factor $1-\alpha(\mathrm{HIF}-1 \alpha)$ is markedly increased (22). HIF-1 $\alpha$ serves key roles in cancer development by regulating the expression of numerous genes involved in proliferation, angiogenesis, metabolism, survival, cell migration and invasion $(22,23)$. Recently, numerous studies have shown that DNA methylation is affected by hypoxia $(24,25)$. Methylation at the C-5 position of cytosine is specifically mediated by DNA methyltransferases. The methylated cytosine $(5-\mathrm{mC})$ of $\mathrm{CpG}$ dinucleotides in the promoter of a gene represses the transcription of this gene (26-28). The ten-eleven-translocation 5-methylcytosine dioxygenase (TET) enzymes catalyze the conversion of 5-mC to 5-hydroxymethylcytosine $(5-\mathrm{hmC})$ to demethylate mammalian DNA (29-31). Elevated 5-hmC levels are associated with increased gene expression (26).

In the present study, the effects of hypoxia on DNA methylation and the expression of TET enzymes in HB HepG2 cells were investigated. The expression of TET enzymes in HepG2 cells exposed to various concentrations of oxygen was assessed using Reverse transcription-quantitative polymerase chain reaction (RT-qPCR), and 5-hmC was detected using immunochemistry and quantified by dot blot. The results of the present study demonstrated that hypoxia regulates DNA methylation through HIF-1 $\alpha$-mediated TET enzymes in HepG2 cells. 


\section{Materials and methods}

Materials. HepG2 cells were purchased from the American Type Culture Collection (Manassas, VA, USA). Anti- $\beta$-actin antibody (clone $\mathrm{AC}-15$ ) and $\mathrm{CoCl}_{2}$ were purchased from Sigma-Aldrich (Merck KGaA, Darmstadt, Germany). Rabbit anti-human HIF-1 $\alpha$ antibody was purchased from Abcam (Cambridge, MA, USA). Pierce ${ }^{\mathrm{TM}}$ ECL Western Blotting substrate and goat anti-rabbit immunoglobulin $\mathrm{G}$ (IgG) antibody conjugated to horseradish peroxidase (HRP) were purchased from Pierce (Thermo Fisher Scientific, Inc., Waltham, MA, USA). Polyvinylidene fluoride (PVDF) membrane was purchased from EMD Millipore (Billerica, MA, USA). Rabbit anti-5-hmC antibody was purchased from Active Motif (Carlsbad, CA, USA). Dulbecco's modified Eagle's medium (DMEM) (REF11965), fetal bovine serum (FBS) (REF16000), trypsin/EDTA, DAPI and donkey anti-rabbit IgG antibody conjugated to Alexa Fluor 594 were purchased from Invitrogen (Thermo Fisher Scientific, Inc.).

Cell culture and hypoxia incubation. HepG2 cells were maintained at $37^{\circ} \mathrm{C}$ in an atmosphere of $95 \%$ air and $5 \% \mathrm{CO}_{2}$ in DMEM containing 10\% heat-inactivated FBS, $100 \mu \mathrm{g} / \mathrm{ml}$ penicillin and $100 \mu \mathrm{g} / \mathrm{ml}$ streptomycin. Cells were subcultured every 5 days with trypsin/EDTA and the medium was changed every other day. Hypoxia was achieved by incubating the cells in an incubator in which the oxygen was replaced by pure nitrogen. The gas proportions used were $21 \% \mathrm{O}_{2}: 21 \% \mathrm{O}_{2}$ and $5 \% \mathrm{CO}_{2} ; 5 \% \mathrm{O}_{2}: 5 \% \mathrm{O}_{2}, 5 \% \mathrm{CO}_{2}$ and $90 \% \mathrm{~N}_{2} ;$ and $1 \% \mathrm{O}_{2}: 1 \%$ $\mathrm{O}_{2}, 5 \% \mathrm{CO}_{2}$, and $94 \% \mathrm{~N}_{2}$.

$R T-q P C R$. Total RNA was extracted using the RNeasy Mini kit according to the manufacturer's protocol (Qiagen China Co., Ltd., Shanghai, China). Further genomic DNA removal was performed using the RNase-Free DNase kit, in accordance with manufacturer's protocol (Qiagen China Co., Ltd.). First-strand complementary DNA (cDNA) was synthesized with oligo-dT or random hexamers as primers, using the SuperScript First-Strand Synthesis System (Invitrogen; Thermo Fisher Scientific, Inc.) according to the manufacturer's protocol. An equal volume mixture of the cDNA products $(50 \mathrm{ng}$ ) was used as templates for PCR amplification. Reactions were performed in a $25-\mu 1$ volume with $\mathrm{iQ}^{\mathrm{TM}} \mathrm{SYBR}$ Green Supermix (Bio-Rad Laboratories, Inc., Hercules, CA, USA), and $200 \mathrm{nM}$ each of forward and reverse primers using an iCyler iQ instrument and iQ software (Version 2.0; Bio-Rad Laboratories, Inc.). Each sample was analyzed in triplicate. PCR conditions included an initial denaturation step of $4 \mathrm{~min}$ at $95^{\circ} \mathrm{C}$, followed by 40 cycles of PCR consisting of $30 \mathrm{sec}$ at $95^{\circ} \mathrm{C}, 30 \mathrm{sec}$ at $60^{\circ} \mathrm{C}$ and $30 \mathrm{sec}$ at $72^{\circ} \mathrm{C}$. Mean quantification cycle $(\mathrm{Cq})$ values from the triplicate PCRs for a gene of interest (GOI) were normalized against the average $\mathrm{Cq}$ values for GAPDH from the same cDNA sample (32). The following primers were used: TET1 forward, 5'-CCGAATCAAGCG GAAGAATA-3' and reverse, 5'-ACTTCAGGTTGCACG GTCTC-3'; TET2 forward, 5'-AGCCCCATCACGTACAAA AC-3' and reverse, 5'-TGTGGTGGCTGCTTCTGTAG-3'; TET3 forward, 5'-CAGCAGCCGAGAAGAAGAAG-3' and reverse, 5'-GGACAATCCACCCTTCAGAG-3'; and GAPDH forward, 5'-GACAACAGCCTCAAGATCATCAG-3' and reverse, 5'-ATGGCATGGACTGTGGTCATGAG-3'. GAPDH served as control.

Production of short hairpin RNA (shRNA) lentiviruses and transduction. A shRNA against human HIF-1 $\alpha$ was cloned into the pLKO.1 vector according to the manufacturer's protocol (Addgene, Inc., Cambridge, MA, USA). The target sequence is 5'-CTGATGACCAGCAACTTGA-3'. pLKO.1, scrambled shRNA (negative control), pMD2.G (used for virus packaging) and psPAX2 (used for virus packaging) were purchased from Addgene, Inc. All constructs were verified by sequencing. Lentiviruses were produced by co-transfecting 293FT cells (Invitrogen; Thermo Fisher Scientific, Inc.) in 10-cm dishes with $10 \mu \mathrm{g}$ pLKO.1-shRNA, $2.5 \mu \mathrm{g}$ pMD2.G and $7.5 \mu \mathrm{g}$ psPAX2 using Lipofectamine 2000 (Invitrogen; Thermo Fisher Scientific, Inc.). Viruses were collected between 16 and $60 \mathrm{~h}$ after transfection, and tittered for $\mathrm{p} 24$ levels using an ELISA kit (ZeptoMetrix Corporation, Buffalo, NY, USA). HepG2 cells were infected with HIF-1 $\alpha$ shRNA at a multiplicity of infection of 20 in the presence of $6 \mu \mathrm{g} / \mathrm{ml}$ polybrene. Virus-containing medium was removed after $16 \mathrm{~h}$ and replaced with fresh DMEM. After $24 \mathrm{~h}$, the cells were used experimentally.

Immunocytochemistry. HepG2 cells $\left(3 \times 10^{4}\right.$ cells $\left./ \mathrm{cm}^{2}\right)$ were plated onto poly-D-Lysine-coated 12 -well plates. Following treatment with 21 or $1 \% \mathrm{O}_{2}$ for $24 \mathrm{~h}$, the cells were washed with PBS; fixed with $4 \%$ formaldehyde for $15 \mathrm{~min}$ at room temperature; permeabilized in $0.1 \%$ Triton X-100 for $20 \mathrm{~min}$; and blocked with 5\% goat serum (Invitrogen; Thermo Fisher Scientific, Inc.) for $1 \mathrm{~h}$ at room temperature. Immunostaining with anti-5-hmC antibody (dilution, 1:1,000; cat. no. 39791) was performed at $4^{\circ} \mathrm{C}$ overnight. Next, donkey anti-rabbit IgG Alexa Fluor 594 (cat. no. A-21207; dilution, 1:2,000) was incubated for $1 \mathrm{~h}$ at room temperature and the nuclei were stained with DAPI for $10 \mathrm{~min}$ at room temperature. Images were acquired on a Zeiss Axio Observer inverted fluorescence microscope (Zeiss AG, Oberkochen, Germany) with lenses corrected for plastic culture plates.

Western blot analysis. HepG2 cells ( $5 \times 10^{6}$ cells) were washed three times with cold PBS and lysed in cold lysis buffer (1\% Triton X-100, $10 \mathrm{mM}$ Tris $\mathrm{pH}$ 7.6, $50 \mathrm{mM} \mathrm{NaCl}, 30 \mathrm{mM}$ sodium pyrophosphate, $50 \mathrm{mM} \mathrm{NaF}, 5 \mathrm{mM}$ EDTA and $0.1 \mathrm{mM} \mathrm{Na}_{3} \mathrm{VO}_{4}$ ) with protease inhibitor cocktail tablets for $20 \mathrm{~min}$. Lysates were centrifuged at $4^{\circ} \mathrm{C}$ at $16,000 \mathrm{x}$ g for $30 \mathrm{~min}$. Supernatant fractions containing equal amounts of total protein $(30 \mu \mathrm{g} / \mathrm{lane})$ were separated by SDS-PAGE $(7.5 \%$ gel), transferred onto a PVDF membrane and analyzed using western blot analysis. Protein concentration was determined using the DC Protein Assay (Bio-Rad Laboratories, Inc.) in accordance with manufacturer's protocol. The membranes were blocked in 5\% non-fat dry milk in Tris-Buffered Saline-Tween 20 (TBST) buffer for $1 \mathrm{~h}$ at room temperature, and immunostained with anti- $\beta$ actin antibody (dilution, 1:1,000; cat. no. A1978) or rabbit anti-human HIF-1 $\alpha$ antibody $\left(1: 1,000\right.$; cat. no. ab51608) in $5 \%$ non-fat milk overnight at $4^{\circ} \mathrm{C}$. Subsequently, the membranes were washed in TBST buffer three times, 5 min each time, at room temperature and the membranes were blotted in goat anti-mouse (cat. no. A28177) 
or goat anti-rabbit (cat. no. A27036) IgG antibody-conjugated to HRP (both: Dilution, 1:2,000; Thermo Fisher Scientific, Inc.) in $5 \%$ non-fat milk, separately, for $2 \mathrm{~h}$ at room temperature. Following washing with TBST, ECL detection (Pierce $^{\mathrm{TM}}$ ECL; Pierce; Thermo Fisher Scientific, Inc.) was performed according to manufacturer's protocol.

5-hmC dot blot. Genomic DNA, from HepG2 cells exposed to either 21 or $1 \%$ oxygen, was extracted using a QIAamp DNA Mini kit in according with manufacturer's protocol (Qiagen China Co., Ltd.). A total of 200 or 500 ng genomic DNA was denatured in $0.1 \mathrm{M} \mathrm{NaOH}$ at $100^{\circ} \mathrm{C}$ for $10 \mathrm{~min}$, followed by the addition of an equal volume of cold $2 \mathrm{M}$ ammonium acetate (pH 7.2). Denatured DNA samples were spotted onto a nitrocellulose membrane and crosslinked using a Stratalinker 2400 UV Crosslinker (Agilent Technologies, Inc., Santa Clara, CA, USA) twice. The membrane was blocked with 5\% non-fat milk for $1 \mathrm{~h}$ and incubated with anti-5-hmC antibody for detection by ECL.

Methylene blue staining. The nitrocellulose membranes contained genomic DNA were immersed in $0.1 \%$ methylene blue (Sigma-Aldrich; Merck KGaA) solution in $0.5 \mathrm{M}$ sodium acetate ( $\mathrm{pH}$ 5.2) and agitated for $10 \mathrm{~min}$ at room temperature. The staining solution was removed and the membranes were washed with successive changes of water until the background was reduced sufficiently to observe the DNA dot.

Statistical analysis. All statistical analyses were performed using SPSS 10.0 (SPSS, Inc., Chicago, IL, USA). Data are expressed as mean \pm standard error of the mean. Unpaired, two-tailed Student's t-tests were performed to evaluate whether two groups were significantly different from each other. For comparison of multiple groups, analysis of variance by Tukey's test was used. $\mathrm{P}<0.05$ was considered to indicate a statistically significant difference.

\section{Results}

Hypoxia increases the expression of TET enzymes in HepG2 cells. The TET enzymes are comprised of three members: TET1, TET2 and TET3 (26). The expression of TET1, TET2 and TET3 was assessed using RT-qPCR of HepG2 cells cultured under 21,5 or $1 \%$ oxygen for 24 h. The HepG 2 cell line is one of the most utilized cell lines in in vitro studies on $\mathrm{HB}$, since it is well characterized and retains numerous hepatocyte-associated features $(33,34)$. As shown in Fig. 1A, the level of TET1 and TET2 messenger RNA (mRNA) in HepG 2 cells cultured under $5 \%$ oxygen was significantly increased compared with that in cells cultured under $21 \%$ oxygen $(\mathrm{P}<0.05)$. No significant changes were observed for TET3 $(\mathrm{P}>0.05)$. When cells were cultured under $1 \%$ oxygen, a significant increase in TET1 and TET2 expression was observed compared with the expression under 21 and $5 \%$ oxygen $(\mathrm{P}<0.01$ and $\mathrm{P}<0.05$, respectively). TET3 expression under $1 \%$ oxygen was also markedly increased compared with that under $21 \%$ oxygen $(\mathrm{P}<0.05)$. Next, the expression of TET enzymes was measured at various time intervals following exposure to $1 \%$ oxygen. As shown in Fig. 1B, the expression of TET1 and TET2 was significantly increased in cells exposed

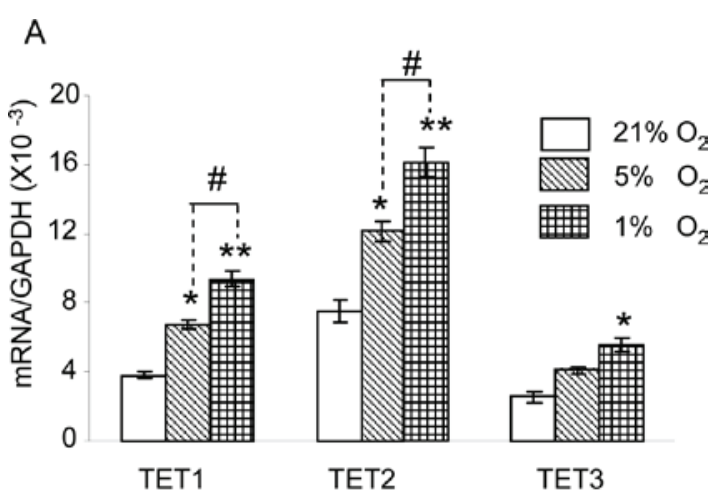

B

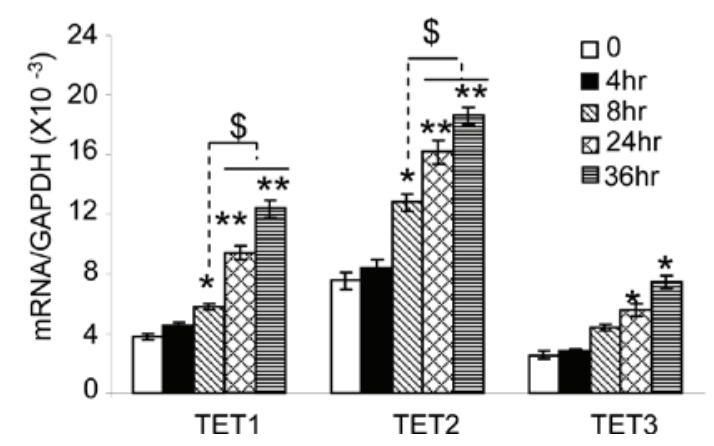

Figure 1. Hypoxia increases the expression of TET1, TET2 and TET3 in HepG2 cells. (A) mRNA levels of TET1, TET2 or TET3 in HepG2 cells cultured under 21,5 or $1 \%$ oxygen for $24 \mathrm{~h} .{ }^{*} \mathrm{P}<0.05$ and ${ }^{* *} \mathrm{P}<0.01$ vs. $21 \%$ oxygen. ${ }^{*} \mathrm{P}<0.05$ vs. $5 \%$ oxygen. (B) mRNA expression levels of TET1, TET2 or TET3 in HepG2 cells exposed to $1 \%$ oxygen for $4,8,16,24$ or $36 \mathrm{~h}$. ${ }^{*} \mathrm{P}<0.05$ and $^{* *} \mathrm{P}<0.01$ vs. cells cultured under $21 \%$ oxygen $(0 \mathrm{~h}) .{ }^{\$} \mathrm{P}<0.05$ vs. cells exposed to $1 \%$ oxygen for $8 \mathrm{~h} . \mathrm{n}=9$ from three independent experiments. TET, ten-eleven-translocation 5-methylcytosine dioxygenase; mRNA, messenger RNA.

to $1 \%$ oxygen for $8 \mathrm{~h}(\mathrm{P}<0.05), 24 \mathrm{~h}(\mathrm{P}<0.01)$ and $36 \mathrm{~h}(\mathrm{P}<0.01)$. The expression of TET1 and TET2 in cells exposed to $1 \%$ oxygen for 24 and $36 \mathrm{~h}$ was higher than that at $8 \mathrm{~h}(\mathrm{P}<0.05)$. TET3 expression in cells exposed to $1 \%$ oxygen for 24 and $36 \mathrm{~h}$ was significantly increased $(\mathrm{P}<0.05)$. These results indicate that hypoxia upregulates TET1, TET2 and TET3 expression in HepG2 cells. TET1 and TET2 expression is more sensitive to hypoxia than TET3 expression.

Hypoxia elevates the cellular 5-hmC level in HepG2 cells. The TET enzymes catalyze the oxidation of 5-mC to 5-hmC. The present study evaluated whether the 5-hmC level was changed upon hypoxia. As shown in Fig. 2, 5-hmC can be detected in the nucleus of HepG2 cells cultured under $21 \%$ oxygen. When HepG 2 cells were cultured in $1 \%$ oxygen for $24 \mathrm{~h}$, greater levels of 5-hmC were observed in the nucleus (Fig. 2D). To quantify the levels of 5-hmC, a dot-blot assay was performed. The 5 -hmC levels in the total DNA from cells exposed to $1 \%$ oxygen for $24 \mathrm{~h}$ were markedly higher than those in cells cultured in $21 \%$ oxygen (Fig. $2 \mathrm{G}$ and $\mathrm{H}$ ). The results show that levels of 5-hmC in HepG2 cells are increased upon hypoxia.

$\mathrm{CoCl}_{2}$ increases the expression of TET enzymes in HepG2 cells. Hypoxia induces biological changes in the cell mainly through stabilizing HIF- $1 \alpha(35) . \mathrm{CoCl}_{2}$ is a known chemical inducer of HIF-1 $\alpha$ expression $(35,36)$. The mRNA levels of 

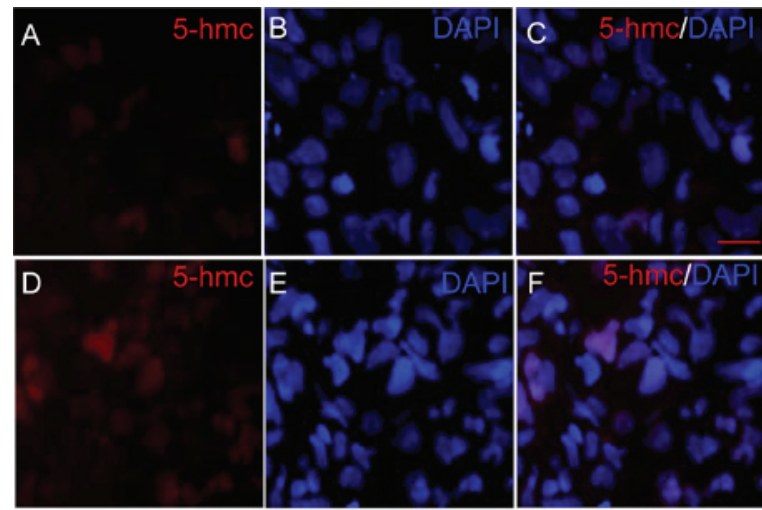

$21 \% \mathrm{O}_{2}$
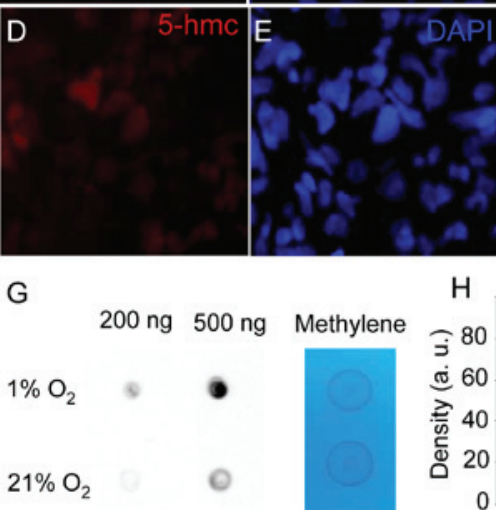

$\mathrm{H}$

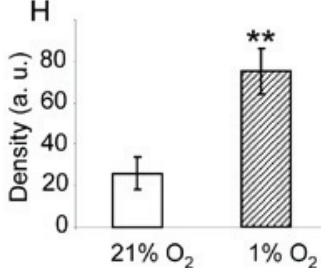

Figure 2. Hypoxia elevates cellular 5-hmC levels in HepG2 cells. HepG2 cells were cultured under (A-C) $21 \%$ or (D-F) $1 \%$ oxygen for $24 \mathrm{~h}$ and then fixed with $4 \%$ paraformaldehyde. Immunohistochemistry was performed using an anti-5-hmC antibody, while the nucleus was stained with DAPI, and the images were merged, as indicated. Scale bar, $10 \mu \mathrm{m}$. (G) The indicated quantities of genomic DNA from HepG2 cells cultured under 21 or $1 \%$ oxygen for $24 \mathrm{~h}$ were blotted with an antibody against 5 -hmC. Methylene blue staining revealed equal loading in the $500 \mathrm{ng}$ genomic DNA lane. (H) Results from 500 ng DNA were then quantified. ${ }^{* *} \mathrm{P}<0.01$ vs. $21 \%$ oxygen. $\mathrm{n}=3$ from three independent experiments. 5-hmc, 5-hydroxymethylcytosine.

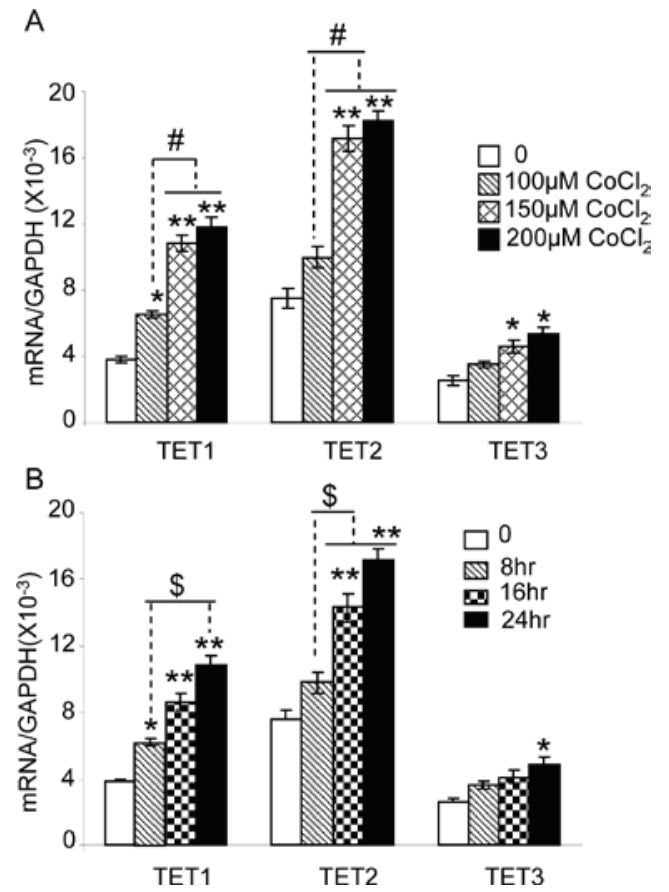

Figure 3. $\mathrm{CoCl}_{2}$ increases the expression of TET1, TET2 and TET3 in HepG2 cells. (A) HepG2 cells were cultured in $21 \%$ oxygen, and then treated with 100,150 or $200 \mu \mathrm{M} \mathrm{CoCl}_{2}$ for $24 \mathrm{~h}$. The mRNA expression level of TET1, TET2 or TET3 was quantified by reverse transcription-quantitative polymerase chain reaction. ${ }^{*} \mathrm{P}<0.05$ and ${ }^{* *} \mathrm{P}<0.01$ vs. untreated cells. ${ }^{*} \mathrm{P}<0.05$ vs. $100 \mu \mathrm{M} \mathrm{CoCl}_{2}$ treatment. (B) HepG2 cells were cultured under $21 \%$ oxygen, and then treated with $150 \mu \mathrm{M} \mathrm{CoCl}_{2}$ for $0,8,16$ or $24 \mathrm{~h}$. The expression levels of TET1, TET2 and TET 3 mRNA are shown. ${ }^{*} \mathrm{P}<0.05$ and ${ }^{* *} \mathrm{P}<0.01$ vs. cells without treatment $(0 \mathrm{~h}) .{ }^{\$} \mathrm{P}<0.05 \mathrm{vs}$. $\mathrm{CoCl}_{2}$ treatment for $8 \mathrm{~h} . \mathrm{n}=9$ from three independent experiments. TET, ten-eleven-translocation 5-methylcytosine dioxygenase; mRNA, messenger RNA.
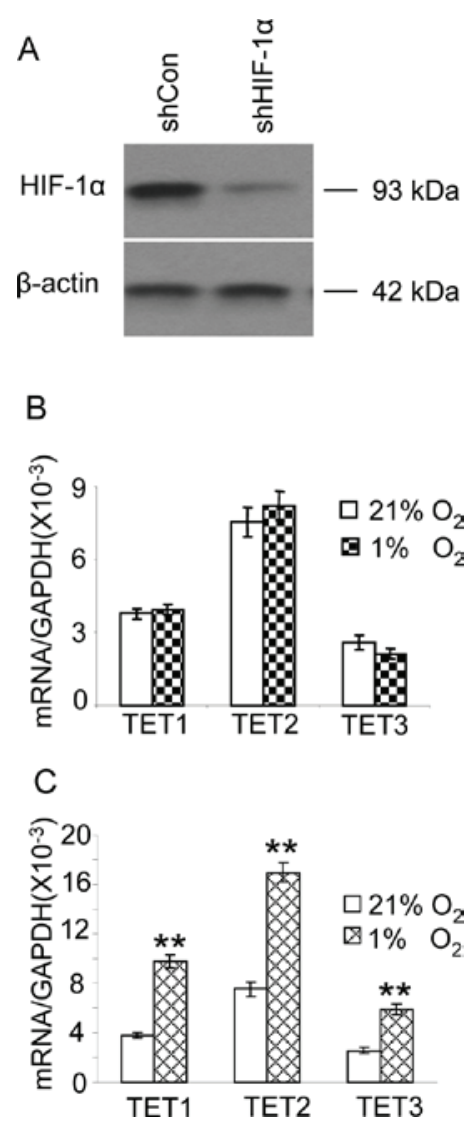

Figure 4. Knockdown of HIF-1 $\alpha$ attenuates the hypoxia-induced expression of TET enzymes. HepG2 cells were transfected with lentivirus expressing shHIF-1 $\alpha$ or shCon for $24 \mathrm{~h}$ and then cultured under $1 \%$ oxygen for additional $24 \mathrm{~h}$. (A) Total cell lysates were blotted using an anti-HIF-1 $\alpha$ antibody (top panel) or an anti- $\beta$-actin (bottom panel) antibody. $\beta$-actin blots revealed equal protein loading. (B) Levels of TET1, TET2 and TET3 mRNA in HepG 2 cells transfected with shHIF-1 $\alpha$ and exposed to 21 or $1 \%$ oxygen for 24 h. (C) Levels of TET1, TET2 and TET3 mRNA in HepG2 cells transfected with shCon and exposed to 21 or $1 \%$ oxygen for $24 \mathrm{~h} .{ }^{* *} \mathrm{P}<0.01$ vs. $21 \%$ oxygen. $\mathrm{n}=9$ from three independent experiments. HIF- $1 \alpha$, hypoxia inducible factor 1- $\alpha$; shHIF-1 $\alpha$, short hairpin RNA against HIF-1 $\alpha$; shCon, scrambled shRNA control; TET, ten-eleven-translocation 5-methylcytosine dioxygenase; mRNA, messenger RNA.

TET1, TET2 and TET3 were measured in HepG2 cells treated with $0,100,150$ or $200 \mu \mathrm{M}$ of $\mathrm{CoCl}_{2}$ for $24 \mathrm{~h}$ in $21 \%$ oxygen (Fig. 3A). TET1 expression was markedly sensitive to $\mathrm{CoCl}_{2}$, and a significant increase in TET1 mRNA expression was observed at $100 \mu \mathrm{M} \mathrm{CoCl}_{2}$ treatment $(\mathrm{P}<0.05)$. TET1 and TET2 expression were significantly increased in cells treated with 150 and $200 \mu \mathrm{M} \mathrm{CoCl}_{2}$, compared with that observed in untreated cells $(\mathrm{P}<0.01)$ or in cells treated with $100 \mu \mathrm{M}$ $\mathrm{CoCl}_{2}(\mathrm{P}<0.05)$. TET3 expression was significantly increased in cells treated with 150 and $200 \mu \mathrm{M} \mathrm{CoCl}_{2}$, compared with that observed in untreated cells $(\mathrm{P}<0.05)$.

The expression of TET enzymes in HepG2 cells exposed to $150 \mu \mathrm{M} \mathrm{CoCl}_{2}$ was assessed at various time intervals (Fig. 3B). TET1 expression was increased following $8 \mathrm{~h}$ of $\mathrm{CoCl}_{2}$ treatment, compared with the expression in untreated cells $(\mathrm{P}<0.05)$. Expression of TET1 and TET2 following 16 and $24 \mathrm{~h}$ of exposure to $\mathrm{CoCl}_{2}$ was significantly higher than that observed in untreated cells $(\mathrm{P}<0.01)$ and in cells treated for $8 \mathrm{~h}$ $(\mathrm{P}<0.05)$. TET3 expression after $24 \mathrm{~h}$ of $150 \mu \mathrm{M} \mathrm{CoCl}_{2}$ treatment was significantly increased compared with that observed 
in untreated cells $(\mathrm{P}<0.05)$. These results indicate that, as hypoxia, $\mathrm{CoCl}_{2}$ treatment increases the expression of TET1, TET2 and TET3 in HepG2 cell in a dose-dependent manner.

HIF-1 $\alpha$ knockdown attenuates the hypoxia-induced expression of TET enzymes. The results of the present study demonstrated that the induced expression of HIF-1 $\alpha$, either by hypoxia or $\mathrm{CoCl}_{2}$, increases the expression of TET1, TET2 and TET3. To investigate whether the hypoxia-induced changes in TET expression are dependent on HIF-1 $\alpha$, the expression of HIF-1 $\alpha$ in HepG2 cells was inhibited with a specific shRNA. HepG 2 cells were treated with a shRNA targeted against HIF- $1 \alpha$ for $24 \mathrm{~h}$; the cells were then cultured in $1 \%$ oxygen for a further $24 \mathrm{~h}$ and the expression of HIF-1 $\alpha$ was assessed by western blot analysis. HIF-1 $\alpha$ expression was markedly reduced compared with that observed in cells transfected with a scrambled shRNA (Fig. 4A). The expression of TET1, TET2 and TET3 was at a similar level in cells transfected with the shRNA against HIF-1 $\alpha$ cultured in either 21 or $1 \%$ oxygen (Fig. 4B). The expression of TET1, TET2 and TET3 in HepG2 cells transfected with scrambled shRNA (control) in $1 \%$ oxygen was significantly increased compared with that observed in cells under $21 \%$ oxygen (Fig. $4 \mathrm{C}, \mathrm{P}<0.01$ ). These results suggest that HIF- $1 \alpha$ knockdown attenuates the increased expression of TET enzymes in hypoxic HepG2 cells.

\section{Discussion}

Aberrant DNA methylation associated with epigenetic modification is a hallmark of cancer pathogenesis $(37,38)$. When a tumor is growing, certain tumor regions, such as those in the center of the tumor, are starved of oxygen due to abnormal vascularization, resulting in a hypoxic microenvironment $(22,23)$. Hypoxia has been demonstrated to induce DNA hypomethylation in normal and hepatoma cells $(24,25)$. The current study demonstrated that hypoxia increases the expression of TET enzymes and elevates cellular 5-hmC levels in $\mathrm{HB}$ HepG2 cells. $\mathrm{CoCl}_{2}$, a chemical inducer of HIF-1 $\alpha(35,36)$, also increases the expression of TET enzymes. HIF-1 $\alpha$ knockdown with a specific shRNA attenuates the hypoxia-induced expression of TET enzymes. The current results indicate that hypoxia controls DNA methylation through HIF-1 $\alpha$-mediated TET enzymes regulation in HepG2 cells.

HepG2 cells were isolated from a human liver biopsy of a 15-year old male with $\mathrm{HB}$, and were originally considered to be a HCC cell line, but were later shown to be a HB cell line (39-41). This cell line is widely utilized in vitro to study $\mathrm{HB}$ due to preserving numerous hepatocyte-associated features $(33,34)$. The present study demonstrates that three TET enzyme family members, namely TET1, TET2 and TET3, are expressed in HepG2 cells and are involved in maintaining the balance of DNA methylation. TET enzymes sequentially oxidize the methyl group of 5-mC to form 5-hmC, and then catalyze the oxidation of 5-hmC to generate 5-formylcytosine and 5-carboxylcytosine $(26,30)$. It has been demonstrated that 5-hmC, as a major epigenetic modification marker, serves a notable role in regulating gene expression in hepatocytes (42). Recent studies have revealed that the expression levels of 5-hmC and TET enzymes are significantly reduced in HCC tissue samples compared with those in non-cancerous liver tissue in the same patient $(18,43)$. Furthermore, the loss of
5 -hmC is associated with the progression of HCC $(18,43)$. Cui et al (21) has demonstrated that the methylation of genomic DNA in HB tissues is significantly lower than that in the adjacent non-tumor tissues, and the hypomethylation in the $\mathrm{CpG}$ sites of the alpha-fetoprotein (AFP) promoter in HB tissues negatively correlates with the expression of AFP. However, the expression of TET enzymes in HB tissues was not reported.

Hypoxia has been regarded as an important factor of the microenvironment, which can induce epigenetic changes in solid tumor cells $(24,25)$. Hypoxia induces the expression of TET1, TET2 and TET3, and elevates the level of cellular 5-hmC in HepG2 cells, which is consistent with a previous report stating that hypoxia induces genomic DNA hypomethylation in HCC Hep3B cells (24). Hypoxia modulates the malignant phenotype of tumor cells through HIF-1 $\alpha$, which regulates the expression of numerous target genes $(23,25)$. The HIF-1 $\alpha$ chemical inducer $\mathrm{CoCl}_{2}$ increases the expression of TET1, TET 2 and TET3 in a dose-dependent manner in HepG2 cells. To substantiate the hypothesis that HIF-1 $\alpha$ upregulates the expression of TET enzymes, HIF-1 $\alpha$ expression was attenuated using a specific shRNA in HepG2 cells. HIF-1 $\alpha$ knockdown significantly inhibited the transcriptional upregulation of TET enzymes upon hypoxia. These results provide direct evidence that hypoxia regulates TET enzymes expression via HIF-1 $\alpha$.

An increase in TET1 expression and in the level of 5-hmC upon hypoxia has been reported in the neuroblastoma SK-N-BE, NBL-WN and LA1-55n (44) cell lines. Wu et al (45) demonstrated that hypoxia increases cellular 5-hmC levels, and upregulates the expression of TET1 and TET3 in breast cancer MCF7 and MDA-MB-231 cell lines, and in primary breast cancer cells. In line with these studies, the results of the present study demonstrate that hypoxia increases cellular 5-hmC levels and the expression of all three TET enzymes in HepG2 cells. TET1 and TET2 expression was more sensitive to hypoxia than TET3 was. The differences on the expression of TET enzymes upon hypoxia among the above studies may be due to the different patterns of gene expression and/or the different signaling pathway involved in cell lines used.

In conclusion, the results of the present study demonstrate that hypoxia induces expression of TET enzymes, a process mediated by HIF-1 $\alpha$, thus increasing cellular 5-hmC levels in HepG2 cells, which could inform on novel strategies for the future development of therapeutic plans.

\section{References}

1. Thomas MB and Zhu AX: Hepatocellular carcinoma: The need for progress. J Clin Oncol 23: 2892-2899, 2005.

2. Calvisi DF, Ladu S, Gorden A, Farina M, Lee JS, Conner EA, Schroeder I, Factor VM and Thorgeirsson SS: Mechanistic and prognostic significance of aberrant methylation in the molecular pathogenesis of human hepatocellular carcinoma. J Clin Invest 117: 2713-2722, 2007.

3. Altekruse SF, McGlynn KA and Reichman ME: Hepatocellular carcinoma incidence, mortality, and survival trends in the United States from 1975 to 2005. J Clin Oncol 27: 1485-1491, 2009.

4. Sia D, Villanueva A, Friedman SL and Llovet JM: Liver cancer cell of origin, molecular class, and effects on patient prognosis. Gastroenterology 152: 745-761, 2017.

5. Herzog CE, Andrassy RJ and Eftekhari F: Childhood cancers: Hepatoblastoma. Oncologist 5: 445-453, 2000.

6. Darbari A, Sabin KM, Shapiro CN and Schwarz KB: Epidemiology of primary hepatic malignancies in U.S. Children. Hepatology 38: 560-566, 2003. 
7. Llovet JM, Burroughs A and Bruix J: Hepatocellular carcinoma. Lancet 362: 1907-1917, 2003.

8. Seeff LB: Introduction: The burden of hepatocellular carcinoma. Gastroenterology 127 (5): S1-S4, 2004.

9. Bisteau X, Caldez MJ and Kaldis P: The complex relationship between liver cancer and the cell cycle: A story of multiple regulations. Cancers (Basel) 6: 79-111, 2014.

10. Thorgeirsson SS and Grisham JW: Molecular pathogenesis of human hepatocellular carcinoma. Nat Genet 31: 339-346, 2002.

11. Dan YY, Riehle KJ, Lazaro C, Teoh N, Haque J, Campbell JS and Fausto N: Isolation of multipotent progenitor cells from human fetal liver capable of differentiating into liver and mesenchymal lineages. Proc Natl Acad Sci USA 103: 9912-9917, 2006.

12. Bell D, Ranganathan S, Tao J and Monga SP: Novel Advances in Understanding of Molecular Pathogenesis of Hepatoblastoma: A Wnt/ $\beta$-Catenin Perspective. Gene Expr 17: 141-154, 2017.

13. Jia D, Dong R, Jing Y, Xu D, Wang Q, Chen L, Li Q, Huang Y, Zhang Y, Zhang Z, et al: Exome sequencing of hepatoblastoma reveals novel mutations and cancer genes in the Wnt pathway and ubiquitin ligase complex. Hepatology 60: 1686-1696, 2014.

14. Eichenmuller M, Trippel F, Kreuder M, Beck A, Schwarzmayr T, Haberle B, Cairo S, Leuschner I, von Schweinitz D, Strom TM and Kappler R: The genomic landscape of hepatoblastoma and their progenies with HCC-like features. J Hepatol 61: 1312-1320, 2014.

15. Koch A, Denkhaus D, Albrecht S, Leuschner I, von Schweinitz D and Pietsch T: Childhood hepatoblastomas frequently carry a mutated degradation targeting box of the beta-catenin gene. Cancer Res 59: 269-273, 1999.

16. Koch A, Weber N, Waha A, Hartmann W, Denkhaus D, Behrens J, Birchmeier W, von Schweinitz D and Pietsch T: Mutations and elevated transcriptional activity of conductin (AXIN2) in hepatoblastomas. J Pathol 204: 546-554, 2004.

17. Tomlinson GE and Kappler R: Genetics and epigenetics of hepatoblastoma. Pediatr Blood Cancer 59: 785-792, 2012.

18. Liu C, Liu L, Chen X, Shen J, Shan J, Xu Y, Yang Z, Wu L, Xia F, Bie P, et al: Decrease of 5-hydroxymethylcytosine is associated with progression of hepatocellular carcinoma through downregulation of TET1. PLoS One 8: e62828, 2013.

19. Nishida N and Goel A: Genetic and epigenetic signatures in human hepatocellular carcinoma: A systematic review. Curr Genomics 12: 130-137, 2011.

20. Rumbajan JM, Maeda T, Souzaki R, Mitsui K, Higashimoto K, Nakabayashi K, Yatsuki H, Nishioka K, Harada R, Aoki S, et al Comprehensive analyses of imprinted differentially methylated regions reveal epigenetic and genetic characteristics in hepatoblastoma. BMC Cancer 13: 608, 2013.

21. Cui X, Liu B, Zheng S, Dong K and Dong R: Genome-wide analysis of DNA methylation in hepatoblastoma tissues. Oncol Lett 12: 1529-1534, 2016

22. Majmundar AJ, Wong WJ and Simon MC: Hypoxia-inducible factors and the response to hypoxic stress. Mol Cell 40: 294-309, 2010 .

23. Semenza GL: Molecular mechanisms mediating metastasis of hypoxic breast cancer cells. Trends Mol Med 18: 534-543, 2012

24. Liu Q, Liu L, Zhao Y, Zhang J, Wang D, Chen J, He Y, Wu J, Zhang Z and Liu Z: Hypoxia induces genomic DNA demethylation through the activation of HIF-1 $\alpha$ and transcriptional upregulation of MAT2A in hepatoma cells. Mol Cancer Ther 10: $1113-1123,2011$

25. Shahrzad S, Bertrand K, Minhas K and Coomber BL: Induction of DNA hypomethylation by tumor hypoxia. Epigenetics 2: $119-125,2007$.

26. Wu $\mathrm{H}$ and Zhang Y: Mechanisms and functions of Tet protein-mediated 5-methylcytosine oxidation. Genes Dev 25 $2436-2452,2011$
27. Das PM and Singal R: DNA methylation and cancer. J Clin Oncol 22: 4632-4642, 2004

28. Jones PA: Functions of DNA methylation: Islands, start sites, gene bodies and beyond. Nat Rev Genet 13: 484-492, 2012.

29. Kohli RM and Zhang Y: TET enzymes, TDG and the dynamics of DNA demethylation. Nature 502: 472-479, 2013.

30. Ito S, Shen L, Dai Q, Wu SC, Collins LB, Swenberg JA, He C and Zhang Y: Tet proteins can convert 5-methylcytosine to 5-formylcytosine and 5-carboxylcytosine. Science 333: 1300-1303, 2011.

31. Tahiliani M, Koh KP, Shen Y, Pastor WA, Bandukwala H, Brudno Y, Agarwal S, Iyer LM, Liu DR, Aravind L and Rao A: Conversion of 5-methylcytosine to 5-hydroxymethylcytosine in mammalian DNA by MLL partner TET1. Science 324: 930-935, 2009.

32. Livak KJ and Schmittgen TD: Analysis of relative gene expression data using real-time quantitative PCR and the 2(-Delta Delta C(T)) method. Methods 25: 402-408, 2001

33. Qiu GH, Xie X, Xu F, Shi X, Wang Y and Deng L: Distinctive pharmacological differences between liver cancer cell lines HepG2 and Hep3B. Cytotechnology 67: 1-12, 2015.

34. Rikhi RR, Spady KK, Hoffman RI, Bateman MS, Bateman M and Howard LE: Hepatoblastoma: A Need for Cell Lines and Tissue Banks to Develop Targeted Drug Therapies. Front Pediatr 4: 22, 2016

35. Wang GL and Semenza GL: General involvement of hypoxia-inducible factor 1 in transcriptional response to hypoxia. Proc Natl Acad Sci USA 90: 4304-4308, 1993.

36. Pugh CW, O'Rourke JF, Nagao M, Gleadle JM and Ratcliffe PJ: Activation of hypoxia-inducible factor-1; definition of regulatory domains within the alpha subunit. J Biol Chem 272: 11205-11214, 1997.

37. Robertson KD: DNA methylation and human disease. Nat Rev Genet 6: 597-610, 2005.

38. Gopalakrishnan S, Van Emburgh BO and Robertson KD: DNA methylation in development and human disease. Mutat Res 647: 30-38, 2008.

39. López-Terrada D, Cheung SW, Finegold MJ and Knowles BB Hep G2 is a hepatoblastoma-derived cell line. Hum Pathol 40: $1512-1515,2009$

40. Capes-Davis A, Theodosopoulos G, Atkin I, Drexler HG, Kohara A, MacLeod RA, Masters JR, Nakamura Y, Reid YA, Reddel RR and Freshney RI: Check your cultures! A list of cross-contaminated or misidentified cell lines. Int J Cancer 127: $1-8,2010$

41. Aden DP, Fogel A, Plotkin S, Damjanov I and Knowles BB: Controlled synthesis of HBsAg in a differentiated human liver carcinoma-derived cell line. Nature 282: 615-616, 1979.

42. Ivanov M, Kals M, Kacevska M, Barragan I, Kasuga K, Rane A, Metspalu A, Milani L and Ingelman-Sundberg M: Ontogeny, distribution and potential roles of 5-hydroxymethylcytosine in human liver function. Genome Biol 14: R83, 2013.

43. Yang H, Liu Y, Bai F, Zhang JY, Ma SH, Liu J, Xu ZD, Zhu HG, Ling ZQ, Ye D, et al: Tumor development is associated with decrease of TET gene expression and 5-methylcytosine hydroxylation. Oncogene 32: 663-669, 2013.

44. Mariani CJ, Vasanthakumar A, Madzo J, Yesilkanal A, Bhagat T, Yu Y, Bhattacharyya S, Wenger RH, Cohn SL, Nanduri J, et al: TET1-mediated hydroxymethylation facilitates hypoxic gene induction in neuroblastoma. Cell Rep 7: 1343-1352, 2014.

45. Wu MZ, Chen SF, Nieh S, Benner C, Ger LP, Jan CI, Ma L, Chen $\mathrm{CH}$, Hishida T, Chang HT, et al: Hypoxia Drives Breast Tumor Malignancy through a TET-TNFo-p38-MAPK Signaling Axis. Cancer Res 75: 3912-3924, 2015. 